\title{
EFFECT OF ENVIRONMENTAL FACTORS IN THE DECOLORIZATION OF REMAZOL BRILLIANT BLUE R BY POLYPORUS SP. S133
}

\author{
TONY HADIBARATA ${ }^{1 *}$, RISKY AYU KRISTANTI ${ }^{2}$ \\ ${ }^{1)}$ Institute of Environmental and Water Resources Management, Universiti Teknologi Malaysia, 81310 Skudai, Johor, Malaysia. \\ ${ }^{2)}$ Department of Chemical and Environmental Engineering. Yamanashi University, Japan. \\ 4-4-37 Takeda, Kofu, Yamanashi, 400-8510 Japan. \\ (Received: May 27, 2011 - Accepted: March 7, 2012)
}

\begin{abstract}
The effects of environmental conditions such as $\mathrm{pH}$, agitation, carbon and nitrogen sources, metal ion, salinity and phenolic compound on the decolorization of the anthraquinone type textile dyestuff Remazol Brilliant Blue R by white rot fungi, Polyporus sp. S133 were investigated. After extensive testing, the best performance took place at $\mathrm{pH} 4$ and decolorization of the dye in liquid effluents was significantly increased by agitation. Compared to other carbon and nitrogen sources tested, glucose and ammonium tartrate gave rise to better decolorization performances. Decolorization of RBBR occurred in the presence of metal ions which are typically found in textile industry effluents. Of all the metal ions tested, $\mathrm{Fe}^{++}$was the most inhibiting of the decolorization. The effect of culture salinity on decolorization was also investigated. Under high-salt conditions, RBBR was also decolorized completely in $6 \mathrm{~d}$. The presence of phenolic compounds inhibited the decolorization at a concentration of $1 \mathrm{mM}$, but protocatechuic acid showed no inhibition. The results indicate that possibly anthraquinone type dyes such as RBBR act as enzyme substrates that are directly oxidized by laccase.
\end{abstract}

Keywords: Anthraquinone dye; Decolorization; Environmental factors; Polyporus sp. S133; Remazol Brilliant Blue R (RBBR)

\section{INTRODUCTION}

Worldwide over 10,000 different synthetic dyes are used in textile, paper, printing, cosmetics and pharmaceuticals. The total world color production is expected to be 800,000 tons per year and at least $10 \%$ of the used dyestuff enters the environment in the form of wastes ${ }^{1,2}$. There are many structural varieties of these materials, including acidic, basic, disperse, azo, diazo, anthraquinone based and metal complex dyes. On the basis of the dyeing process, textile dyes are classified as reactive dyes, direct dyes, disperse dyes, acid dyes, basic dyes and vat dyes. It is estimated that $10-15 \%$ of the dyes are lost in the effluent during the dyeing process ${ }^{3}$. Since most of the dyes are very stable to light, temperature and the attack by microorganisms, which makes them recalcitrant, these compounds are difficult to remove from effluents by conventional biological processes such as activated sludge treatment ${ }^{4}$. Remazol Brilliant Blue R (RBBR) is one of the most important dyes in the textile industry, and is frequently used as starting material in the production of polymeric dyes. However, RBBR is an anthracene derivative that represents an important class of toxic and recalcitrant organopollutants.

The literature suggests that there is great potential in developing microbiological decolorization systems with total color removal, a feat that in some cases happens within a few hours ${ }^{5,6}$. White rot fungi (WRF) is the most efficient class of microorganisms in breaking down synthetic dyes ${ }^{7}$. Indeed, white rot fungi are the most efficient ligninolytic organisms capable of degrading various types of dyes such as azo, heterocyclic, reactive and polymeric dyes. WRF have long been known to decolorize dyes ${ }^{9}$, a property that is based on their ability to produce one or more extracellular lignin-modifying enzymes (LME). These versatile fungi can degrade not only a broad range of recalcitrant dyes but also the complex polymer ${ }^{10,11}$. There is a considerable number of recent reports on decolorization and degradation of individual synthetic dyes by WRF ${ }^{12-14}$. Previous research has reported that WRF such as Dichomitus squalens, Daedalea flavida, and Irpex flavus have been selected and applied in different industries for their potential to decolorize eight dyes. D. squalens and I. flavus were found to be competitive dye decolorizers in comparison to the much studied white rot fungus $P$. chrysosporium. Schizophyllum commune was used for the decolorization of the reactive synthetic dye Cibacron Red FN-2BL ${ }^{15}, 16$. However, very few studies have been reported on the decolorization of RBBR by the Polyporus genus. The major objective of our study was to investigate the effects of various environmental conditions such as agitation, $\mathrm{pH}$, carbon and nitrogen sources, metal ion, $\mathrm{NaCl}$ concentration, and the presence of phenolic compounds on the decolorization efficiency of anthraquinone type synthetic dyes by Polyporus sp. S133.

\section{EXPERIMENTAL}

Chemicals

Salicylic acid, protocatechuic acid and catechol were obtained from Tokyo Chemical Industry Co. Ltd. (Tokyo, Japan). Malt extract and polypeptone were purchased from Difco (Detroit, USA). RBBR was provided by Sigma (St. Louis, USA). The structure of RBBR is shown in Figure1. All other chemicals were purchased from Wako Pure Chemical Industry Co. Ltd. (Osaka, Japan) at the highest purity available.

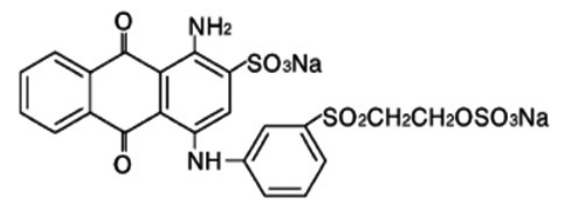

Figure 1. The chemical structures of Remazol Brilliant Blue R.

Microorganism and culture condition

Polyporus sp. S133, a white rot fungus, was selected for this study for its ability to degrade Polycyclic Aromatic Hydrocarbons ${ }^{17,18}$. The composition of the nutrient medium in the decolorization studies was (g/l): malt extract (20), glucose (20), and peptone (1). The pure culture was maintained on nutrient agar slants at $4{ }^{\circ} \mathrm{C}$ by transferring culture once in a month.

Experimental procedure

Experiments were performed using 100-ml Erlenmeyer flasks in an incubation room. The flasks were prepared in triplicate and contained $20 \mathrm{ml}$ nutrient media with dyestuff. A 5 -mm active plug cut from the pure fungal culture grown on agar plates was used for inoculation of flasks under sterile conditions. Control flasks contained only dyestuff and nutrients, but no fungi. The cultures were incubated for 6 days at a static place. All the environmental factors were tested with a RBBR concentration of $100 \mathrm{ppm}$. Samples (triplicate flasks) were taken periodically, centrifuged at $8000 \mathrm{~g}$ for $20 \mathrm{~min}$ at $15^{\circ} \mathrm{C}$, and the clear supernatant obtained was used to determine the rate of decolorization spectrophotometrically by reading absorbance in a UV-Vis Spectrometer at ${ }_{\text {max }}$ $(595 \mathrm{~nm})^{19}$. The percentage of decolorization was calculated as follows:

Decolorization $(\%)=\left(1-\frac{C}{C_{0}}\right) \times 100$

where $\mathrm{C}_{0}$ is the initial dye concentration and $\mathrm{C}$ is the final dye concentration 20 
Effect of $p H$ and agitation on RBBR decolorization.

To study the effect of $\mathrm{pH}$ on the decolorization of RBBR, the dye was incubated at room temperature at different $\mathrm{pH}$ values using buffers; citrate for $\mathrm{pH}$ 3-5 and phosphate for $\mathrm{pH}$ 6-8 to keep the media $\mathrm{pH}$ constant. The effect of agitation on decolorization was conducted by shaking the culture in a rotary shaker at $120 \mathrm{rpm}$. For each $\mathrm{pH}$ and shaking value a reaction mixture without the fungi was prepared under the same conditions to act as a blank to detect a possible change of color which is not due to enzyme activity.

Effect of different carbon and nitrogen sources on RBBR decolorization

The effect of carbon sources on dye decolorization was tested with fructose, sucrose, glucose, and starch. All carbon sources were used at a final concentration of $5 \mathrm{~g} / \mathrm{l}$. The effect of nitrogen sources on dye decolorization was tested with yeast extract, polypeptone, ammonium tartrate and ammonium nitrate. All nitrogen sources were used at a final concentration of $2.5 \mathrm{~g} / \mathrm{l}$. The reaction mixture was as described above.

Effect of metal ions and $\mathrm{NaCl}$ concentration on RBBR decolorization.

In order to determine the effect of metal ions on the decolourization of $\mathrm{RBBR}$, in each case $10 \mathrm{mM}$ of $\mathrm{MnCl}_{2}, \mathrm{FeCl}_{2}, \mathrm{MgSO}_{4}$, and $\mathrm{CuCl}_{2}$ were allowed to incubate at $25{ }^{\circ} \mathrm{C}$ in a reaction mixture which consisted of $50 \mathrm{mM}$ acetate buffer at $\mathrm{pH} 5$ and 100ppm RBBR. The effect of $\mathrm{NaCl}$ concentration was determined upon addition of 100,300 , and $500 \mathrm{mM}$ of $\mathrm{NaCl}$.

\section{Effect of phenolic compounds on RBBR decolorization}

The effect of phenolic compounds on dye decolorization was tested with salicylic acid, protocatechuic acid, gentisic acid and catechol. All compounds were used at a final concentration of $1 \mathrm{mM}$. The reaction mixture was processed as described above.

\section{RESULTS AND DISCUSSION}

Most previous studies focused on the lignin-degrading enzymes of $P$. chrysosporium and $T$. versicolor. More recently, there has been a growing interest in studying the lignin-modifying enzymes of a wide range of white rot fungi with the expectation of finding better lignin degrading systems for use in various biotechnological applications. Hence, in the present work, Polyporus sp. S133 was explored for its dye decolorization ability.

Effect of agitation and $\mathrm{pH}$ on dye decolorization

Figure 2 indicates that almost $92 \%$ of dye decolorization was achieved in agitated cultures in one day after addition of the dye, as compared to $21 \%$ decolorization in stationary cultures. The increased efficiency in dye decolorization could be due to the physiological state of fungus as pellets together with increased mass transfer between the cells and the medium. The biodegradation ability of the white rot fungi has been attributed to the extracellular activity of oxidative lignin modifying enzymes such as laccase. Previous studies indicated that the highest laccase production occurs in agitated cultures which in turn leads to maximum decolorization. In stationary cultures, formation of a mat on the surface results in the limitation of oxygen transfer to the cells under the surface and in the medium giving rise to oxygen restriction, which inhibits the oxidative enzymes and prevents decolorization ${ }^{21}$. Hence, a lower rate of decolorization was achieved in stationay cultures. It was also observed that with such a static culture dye decolorization was generally due to the sorption of the dyes on the fungal mat. Furthermore, agitation has two main effects on the cultivation of fungi. First, it is important to ensure the supply of nutrients, especially oxygen. Good mixing, mass and heat transfer require a threshold level of agitation. On the other hand, a high agitation rate leads to a high energy dissipation rate connected with high shear stress, which may result in fragmentation and damage of cells and the mycelial network $22-25$.

The optimal growth $\mathrm{pH}$ for Polyporus sp. S133 is $\mathrm{pH} 4$. However, a pH above or below that value is not suitable for practical wastewater treatment operations. Indeed, when decolorization experiments with the fungi were conducted at different initial $\mathrm{pH}$ values (Figure 3 ) decolorization of RBBR occurred at $\mathrm{pH} 3-8$ and was optimal at $\mathrm{pH} 4(97 \%)$ in one day. Decolorization of RBBR at $\mathrm{pH}$ values of $3,6,7$, and 8 was inhibited on the first day of incubation, but increased after 6 days. The initial $\mathrm{pH}$ of the flasks processed at $\mathrm{pH} 4.5$ remained fairly constant throughout the 6 days of incubation whereas the $\mathrm{pH}$ of the media having a higher initial $\mathrm{pH}$ decreased and showed a declining trend. An increase in the initial $\mathrm{pH}$ beyond 3 gave lower manganese peroxidase $(\mathrm{MnP})$ activities leading to lesser effluent color loss. The 3-7 $\mathrm{pH}$ range for dye decolorization by lignolytic enzymes of different WRF has also been previously reported. Similarly to the results of Levin et al. who found laccase to be the major enzyme for $C$. versicolor, the major ligninolytic enzyme produced by Polyporus sp. S133 was also laccase. However, it has also been stated that the enzyme system responsible for dye degradation and the pattern of its expression may vary in response to dyes of different chemical structures present in the effluents ${ }^{26,27}$.

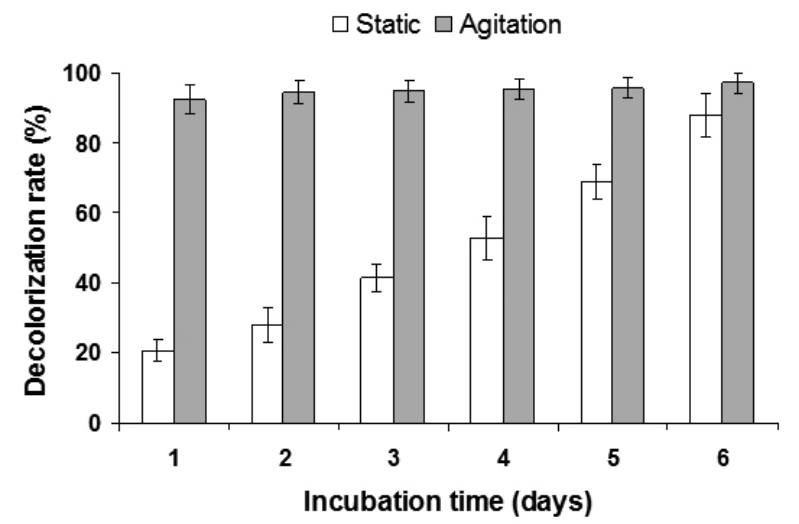
S133.

Figure 2. Effect of agitation on RBBR decolorization by Polyporus sp.

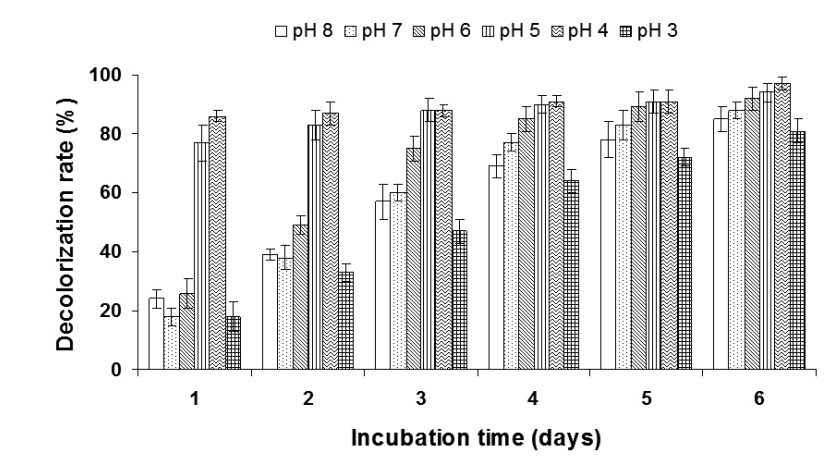

Figure 3. Effect of pH on RBBR decolorization by Polyporus sp. S133.

Effect of different carbon and nitrogen sources on RBBR decolorization.

Figure 4 shows the effect of different carbon sources on RBBR decolorization. In all the carbon sources tested, the lowest dye decolorization was observed with starch $(53 \%)$ after three days of incubation. When glucose was used as the carbon source, $85 \%$ decolorization was achieved in three days of incubation; during the same period for sucrose and fructose decolorization reached 63 and $64 \%$, respectively. The decolorization performance with starch was not very effective. Absorbance values decreased slowly, resulting in $53 \%$ color removal after 3 days of incubation. Decolorization after 5 days was only $79 \%$ as compared to nearly $100 \%$ decolorization with glucose. Color removal in the control flask was negligible, which was due mainly because of adsorption of the dyestuff on the insoluble fraction of starch. On the basis of these results, glucose seemed to be the most suitable carbon source for the fungi to achieve decolorization of RBBR. Fructose, sucrose and starch may be used as the carbon source, but they lead to lower decolorization performances as compared to glucose ${ }^{28}$. In contradiction with the results of Asgher et al. who found $\mathrm{MnP}$ to be the major enzyme for $C$. versicolor IBL-04, the major ligninolytic enzyme produced by Polyporus sp. S133 was laccase. Starch (1\%) as the carbon source has been reported to give maximum MnP activity ${ }^{29}$. Hence, glucose was selected as the best carbon source for dye decolorization. No dye decolorization was observed in the control flasks without inoculum.

Figure 5 shows the effect of different nitrogen sources on RBBR decolorization. Organic nitrogen sources were not effective in RBBR decolorization. When yeast extract and polypeptone were used, only 50 and $45 \%$, respectively, of dye decolorization was achieved. Inorganic nitrogen sources were more efficient in RBBR decolorization. Among the different nitrogen sources, ammonium tartrate was the best leading to $95 \%$ RBBR decolorization in $6 \mathrm{~d}$, while only $90 \%$ decolorization was achieved in $6 \mathrm{~d}$ with ammonium nitrate. Hence, ammonium tartrate was selected as the best nitrogen source. 


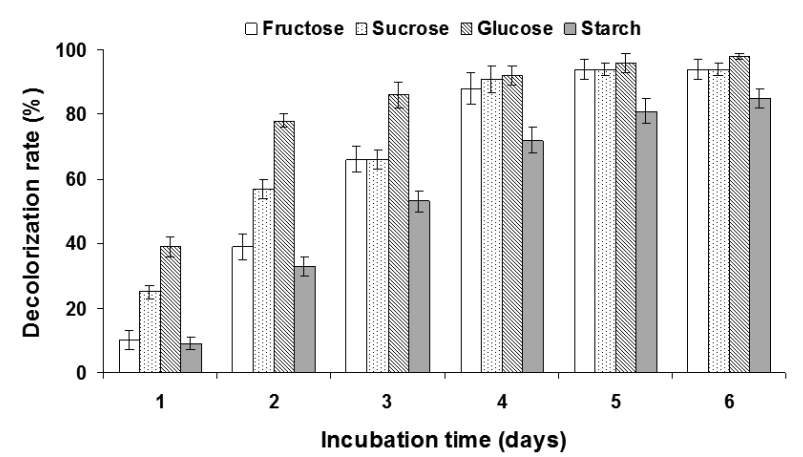

Figure 4. Effect of carbon sources on RBBR decolorization by Polyporus sp. S133.

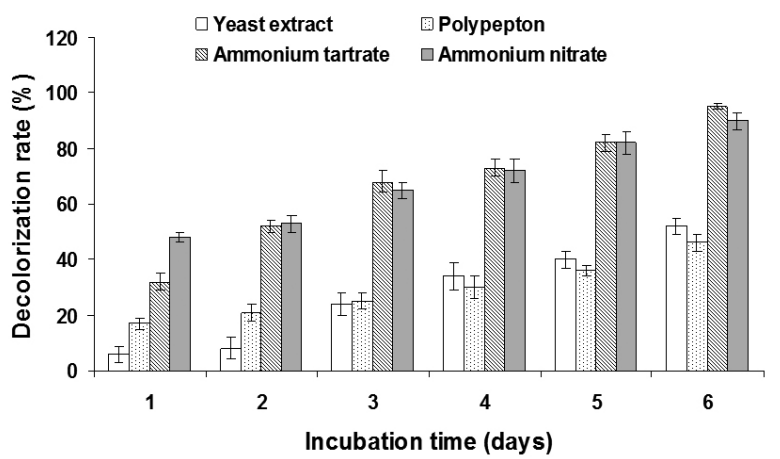

Figure 5. Effect of nitrogen sources on RBBR decolorization by Polyporus sp. S133.

Effect of metal ions and $\mathrm{NaCl}$ concentration on RBBR decolorization.

Figure 6 shows that in the presence of $\mathrm{Fe}^{2+}, \mathrm{Mg}^{2+}, \mathrm{Mn}^{2+}$, and $\mathrm{Cu}^{2+}$ the decolorization of RBBR was affected by the metal ions. Addition of $\mathrm{Cu}^{2+}$, $\mathrm{Mg}^{2+}, \mathrm{Mn}^{2+}$ gave positive results while decolorization was inhibited by addition of $\mathrm{Fe}^{2+}$. The highest decolorization was shown upon addition of $\mathrm{Cu}^{2+}(95 \%)$. Copper is a component of the active site of laccases. It has been observed in previous studies that the addition of $\mathrm{Cu}^{2+}$ enhanced the laccase activity ${ }^{30}$. Rodriguez Couto et al. have also confirmed that the laccase from Trametes hirsuta was steady at a low concentration in the presence of all the metal ions tested except for $\mathrm{CrO}_{4}^{2-}, \mathrm{Zn}^{2+}, \mathrm{Cu}^{2+}, \mathrm{Cd}^{2+}$, and especially $\mathrm{Hg}^{2+}$. When the concentration was increased to $100 \mathrm{mM}$, laccase stability decreased in the presence of all the metals assayed, in particular against $\mathrm{Fe}^{2+}$. Indeed, in the presence of $\mathrm{Fe}^{2+}$, a severe inhibition of the decolorization (less than $80 \%$ decolorization) was observed. This could be explained by the instability of some enzymes especially laccase in the presence of $\mathrm{Fe}^{2+}$ at high concentration. The purified laccase of T. trogii was completely inhibited by $\mathrm{Fe}^{2+}$, which may be due to interaction of $\mathrm{Fe}^{2+}$ with the electron transport system of laccase ${ }^{30}$.

The effects of salinity on RBBR decolorization performance are shown in Figure 7 . The results show that the decolorization rates remained approximately identical when the $\mathrm{NaCl}$ concentration was increased from $100 \mathrm{mM}$ to 500 $\mathrm{mM}$. The maximal decolorization rate was about $97 \%$ at $100 \mathrm{mM} \mathrm{NaCl}$ after $6 \mathrm{~d}$ of incubation. From these available results, we could conclude that the Polyporus sp. S133 has the ability to tolerate high-salt conditions and still lead to a high-rate decolorization performance. Reports on decolorization of azo dyes under high-salt conditions confirmed that it was a good choice to treat hyper-saline wastewater with salt-tolerant microorganisms or consortium ${ }^{31}$. In this study, acclimatization of efficient and stable salt-tolerant microbial community capable of decolorizing anthraquinone dyes was proved available. Furthermore, little decrease in decolorization effectiveness was observed with higher salinity, compared with that conducted with lower salinity.

Effect of phenolic compounds on RBBR decolorization.

Laccases are multicopper oxidases that catalyze the one-electron oxidation of substituted phenols, anilines, and aromatic thiols to their corresponding radicals with the concomitant reduction of molecular oxygen to water. The basis of the laccase-mediator concept is the use of low-molecular-weight phenolic compounds that, once oxidized by the enzyme to stable radicals, act as redox mediators, oxidizing other compounds that in principle are not substrates of laccase. In addition phenolic compounds were shown to be efficient laccase mediators ${ }^{32}$. The effect of phenolic compounds on the decolourization of RBBR was tested by addition of salicylic acid, catechol, protocatechuic acid and gentisic acid at $1 \mathrm{mM}$ (Figure 8). Addition of salicylic acid, catechol, and gentisic acid appeared to inhibit the RBBR decolorization while protocatechuic acid showed no inhibition or activation on the RBBR. This could be explained by the fact that anthraquinone dyes such as RBBR act as enzyme substrates that are directly oxidized by laccase while decolourization of azo and indigo dyes involves some small molecule metabolites like HBT as mediators. On the other hand, the inhibition of the decolourization could be due to a toxic effect of the high concentration of the nitroxide radical resulting from laccase oxidation of $\mathrm{HBT}^{33}$.

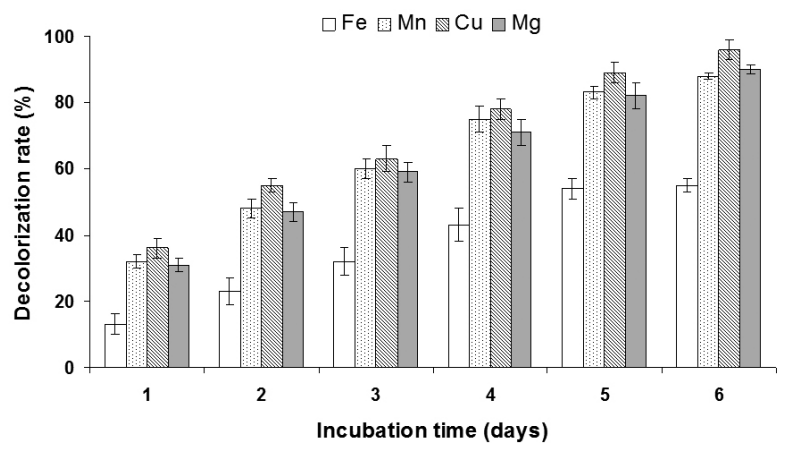

Figure 6. Effect of metal ions on RBBR decolorization by Polyporus sp. S133.

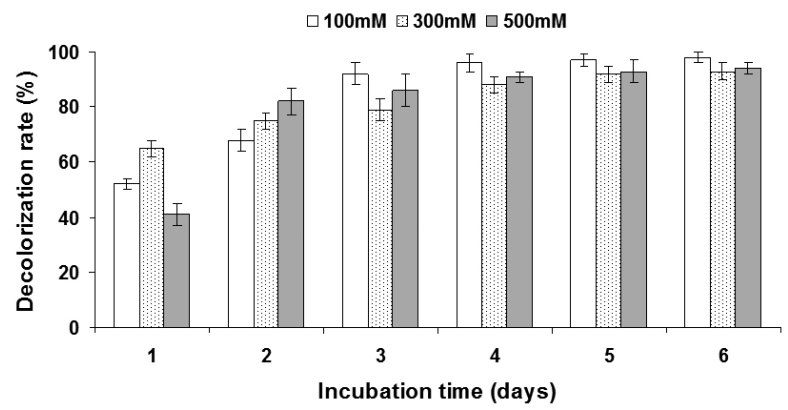

Figure 7. Effect of $\mathrm{NaCl}$ concentration on RBBR decolorization by Polyporus sp. S133.

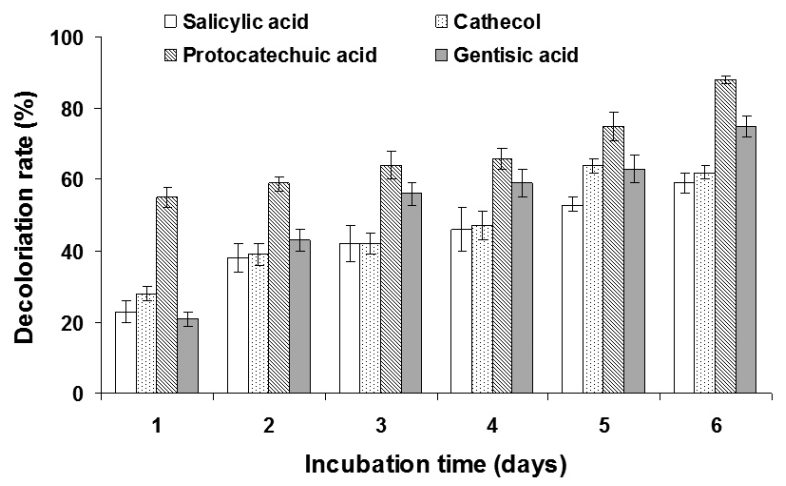

Figure 8. Effect of phenolic compounds on RBBR decolorization by Polyporus sp. S133.

\section{CONCLUSIONS}

The effects of various environmental factors on decolorization of RBBR by Polyporus sp. S133 were investigated. Decolorization increases at $\mathrm{pH} 5$ and agitation. Glucose and ammonium tartrate were the most suitable carbon and nitrogen sources among others tested. Testing of metal ions at a concentration 
of $10 \mathrm{mM}$ indicated that $\mathrm{Fe}^{2+}$ was the most inhibiting while $\mathrm{Cu}^{2+}$ was the most suitable for decolorization. Furthermore, under high-salt conditions RBBR was also decolorized completely in $6 \mathrm{~d}$. The presence of phenolic compounds was found to be inhibiting for the decolorization at a concentration of $1 \mathrm{mM}$, while only protocatechuic acid showed no inhibition. This is an indication that possibly anthraquinone dyes such as RBBR act as enzyme substrates that are directly oxidized by lac

\section{ACKNOWLEDGEMENTS}

Part of this research was financially supported by an Institutional Research Grant from the Universiti Teknologi Malaysia (Vote No. 77552), which is gratefully acknowledged.

\section{REFERENCES}

1. G. Palmieri, G. Cennamo, Enzyme Microb. Technol. 36, 17, (2005).

2. L. Levin, L. Papinutti, F. Forchiassin, Biores. Technol. 94, 169, (2004).

3. H. Zollinger, H. Color chemistry-synthesis, properties and application for organic dyes and pigments. VCH Publications, New York, (1987).

4. P.K. Wong, P.Y. Yuen, Water Res. 30, 1736, (1996).

5. D.S.L. Balan, R.T.R. Monteiro, J. Biotechnol. 89, 141, (2001).

6. M.A.M. Martins, N. Lima, A.J.D. Silvester, M.J. Queiroz, Chemosphere $52,967,(2003)$

7. M.J. Lopez, G. Guisado, M.C. Vargas-Garcia, F.S. Estrella, J. Moreno, Enzyme Microb. Technol. 40, 42, (2006).

8. C. Novotny, K. Svobodova, A. Kasinath, P. Erbanova, Int. Biodeter Biodegrad. 54, 215, (2004).

9. J.K. Glenn, M.H. Gold, Appl. Environ. Microbiol. 45, 1741, (1983).

10. J.A. Field,.E. Jong, G. de Feikoo-Costa, J.A.M. de Bont, Trends Biotechnol. 11, 44, (1993).

11. D.P. Barr, S.D. Aust, Environ. Sci. Technol. 28, 78, (1994).

12. H.R. Hamedaani, A. Sakurai, M. Sakakibara, Dyes Pigm. 72, 157, (2007).
13. M. Tavaker, K. Svobodova, J. Kuplenk, C. Novotny, J. Pavko, Acta Chim. Slov. 53, 338, (2006).

14. M. Asgher, S.A.H. Shah, M. Ali, R.L. Legge, World J. Microbiol. Biotechnol. 22, 89, (2006).

15. M. Chander, D.S. Arora, Dyes Pigm. 72, 192, (2007).

16. H.N. Bhatti, N. Akram, M. Asgher, Appl. Biochem. Biotechnol. 149, 255, (2007).

17. T. Hadibarata, S. Tachibana, M. Askari, J. Microbiol. Biotechnol. 21, 299, (2011).

18. T. Hadibarata, A.R.M. Yusoff, R.A. Kristanti, Water Air Soil Poll. 223, 933, (2012).

19. D. Rajkumar, B.J. Song, J.G. Kim, Dyes Pigm. 71, 1, (2007).

20. E. Sayan, Chem. Eng. 119, 175, (2006).

21. J. Swamy, J.A. Ramsay, Enzyme Microb. Technol. 24, 130, (1999).

22. A. Amanullah, P. Justen, A. Davies, G.C. Paul, A.W. Nienow, C.R. Thomas, Biochem. Eng. J. 5, 109, (2000).

23. Z.L. Li, V. Shukla, A.P. Fordyce, A.G. Pedersen, K.S. Wenger, M.R. Marten, Biotechnol. Bioeng. 70, 300, (2000).

24. A. Mittard, J.P. Riba, Biotechnol. Bioeng. 32, 835, (1988).

25. J. Nielsen, C.L. Johansen, M. Jacobsen, P. Krabben, J. Villadsen, Biotechnol. Progr. 11, 93, (1995).

26. L. Levin, L. Papinutti, F. Forchiassin, Biores. Technol. 94, 169, (2004).

27. C.G. Boer, L. Obici, C.G. Souza, R.M. Peralta, Biores. Technol. 94, 107, (2004).

28. I.K. Kapdana, F. Kargia, G. McMullanb, R. Marchantb, Enzyme Microb. Technol. 26, 381, (2000).

29. M. Asgher, N. Azim, B.N. Bhatti, Biochem. Eng. J. 47, 61, (2009).

30. S. Rodriguez Couto, M. Sanroma'n, G.M. Gu" bitz, Chemosphere 58, 417, (2005).

31. S. Asad, M.A. Amoozegar, A.A. Pourbabaee, M.N. Sarbolouki, S.M. Dastgheib, Bioresour. Technol. 98, 2082, (2007).

32. S. Camarero, D. Ibarra, M.J. Martınez, A.T. Martınez, Appl. Environ. Microbiol. 71, 1775, (2005).

33. T. Mechichi, N. Mhiri, S. Sayadi, Chemosphere 64, 998, (2006). 